\title{
A Community based Study of Anaemia Burden using Hemocue 201 in Eastern India
} Vikas Bhatia ${ }^{1}$, Swayam Pragyan Parida ${ }^{2}$, Preetam B Mahajan ${ }^{3}$, Durgesh Prasad Sahoo ${ }^{4}$, Sourav Bhattacharjee ${ }^{5}$ ${ }^{1}$ Prof and Head, Department of Community Medicine and Family Medicine, All India Institute of Medical Science Bhubaneswar, Odisha, India; ${ }^{2}$ Associate Professor, Department of Community Medicine and Family Medicine, All India Institute of Medical Science Bhubaneswar, Odisha, India; ${ }^{3}$ Professor, Department of Community Medicine, Pondicherry Institute of Medical Sciences, Puducherry, India; ${ }^{4}$ Senior Resident, Department of Community Medicine and Family Medicine, All India Institute of Medical Science Bhubaneswar, Odisha, India; ${ }^{5}$ Nutrition Specialist, UNICEF, Odisha, India

\begin{tabular}{|c|c|c|c|c|c|c|c|}
\hline Abstract & Introduction & Methodology & Results & Conclusion & $\underline{\text { References }}$ & Citation & Tables / Figures \\
\hline \multicolumn{8}{|c|}{ Corresponding Author } \\
\hline \multicolumn{8}{|c|}{$\begin{array}{l}\text { Dr. Swayam Pragyan Parida, Associate Professor, Department of Community Medicine and Family } \\
\text { Medicine, All India Institute of Medical Science Bhubaneswar, Odisha, India - } 751019 \\
\text { E Mail ID: swayam.aiims@gmail.com }\end{array}$} \\
\hline
\end{tabular}

\section{Citation}

Bhatia V, Parida SP, Mahajan PB, Sahoo DP, Bhattachargee S. A Community based Study of Anaemia Burden using Hemocue 201 in Eastern India. Indian J Comm Health. 2020;32(2):365-370.

Source of Funding: UNICEF Conflict of Interest: None

\section{Article Cycle}

Received: 31/03/2020; Revision: 15/04/2020; Accepted: 08/05/2020; Published:30/06/2020 This work is licensed under a Creative Commons Attribution 4.0 International License.

\section{Abstract}

Background: India is facing a serious burden of anemia where majority of the women (51\%) of reproductive age suffer from anemia. Though there are many programs being run for decades to fight anaemia, it still persist to be a major health challenge in Odisha where around half of the women and children are anemic (children age 6-59 months; 44.6\%, pregnant women of age 15-49; 47.6\%, all women of age 15-49 years; 51.0\%). Objectives: AllMS Bhubaneswar, in partnership with Govt. of Odisha and UNICEF aimed to assess the burden of anaemia in the state. Methods: This cross-sectional study was conducted amongst 3974 beneficiaries between March to July 2016. Hemoglobin estimation was done using Hemocue 201. Results: Prevalence of mild, moderate and severe anemia was observed to be $39-58 \%, 7-20 \%$ and $1-3 \%$, respectively in 4 districts. Coverage of iron folic acid tablets amongst adolescent girls, adolescent boys, pregnant women, lactating mothers, and women of reproductive age groups were 38\%, 16\%, 73\%, 46\%, 11\% respectively. Conclusion: The study has shown that prevalence of severe and moderate anaemia has decreased to a greater extent, however the prevalence of mild anaemia is still very high.

\section{Keywords}

Anaemia; NIPI; Hemoglobin; Prevalence; Hemocue; Iron Folic Acid Tablet

\section{Introduction}

Anaemia, defined as a low blood hemoglobin concentration, is considered to be a major public health problem affecting low, middle and high-income countries. It has significant adverse impact per se on the health consequences, as well as on socio-economic development. (1,2) According to the report of "The Global prevalence of Anaemia in 2011, Geneva", anaemia affects around 800 million children and women.(3) A worldwide systemic analysis indicated that the global prevalence of anaemia among non-pregnant women was 29\% (24-35), pregnant women 38\% (34-43) and children 43\% (38-47) with highest prevalence in South Asia (non-pregnant women $53 \%$, pregnant women $53 \%$ and children $70 \%$ ).(4)
In South Asia, India has a high burden of anaemia where more than half of the women (51\%) of reproductive age suffer from anaemia (Global Nutrition Report 2017).(5) According to National Family Health Survey 4 (NFHS 4) data, the prevalence of anaemia exceeds 50 percent in almost all the groups of people except men in the age group of 15-49 years (children age 6-59 months; $58.5 \%$, pregnant women of age $15-49 ; 50.3 \%$, all women of age $15-49$ years; $53 \%$ and men age $15-49$ years; $22.7 \%) .(6)$ National Nutritional Monitoring Bureau shows the prevalence of anaemia among adolescents to be as high as $70 \%$. (7) Though the prevalence of anaemia shows a downward trend in 2015-16 (NFHS 4) compared to 200506 (NFHS 3), still it is high among most vulnerable groups (pregnant women, adolescents and children). (8) 
Odisha is a state in the eastern part of India with a population of 43 million with $22.1 \%$ of tribal population.(9) There are many tribal groups spread across the state with different languages and cultures. The topography also makes most of the areas hard to reach to deliver health care services. Though there are many programs being run for decades to fight anaemia, it still persist to be a major health challenge in Odisha where around half of the women and children are anemic (children age 6-59 months; $44.6 \%$, pregnant women of age $15-49 ; 47.6 \%$, all women of age $15-49$ years; $51.0 \%) .(10)$ To address this issue, the National iron Plus Initiative (NIPI) program which is the most ambitious and comprehensive anaemia control program was launched in 2013 by Ministry of Health and Family Welfare (MOHFW), Govt. of Odisha with strategies targeting beneficiaries across life cycle.(11)

Odisha was a forerunner of NIPI implementation among states having a very high prevalence of anemia and needed definite attention.

\section{Aims \& Objectives}

To understand the burden of anemia among various age groups.

\section{Material \& Methods}

It was a cross-sectional study conducted in four districts of Odisha having a total population around 5.5 million. A total of 3974 beneficiaries were interviewed from March to July 2016.

Selection of districts: To understand the whole scenario of Odisha, it was decided to take one representative district from each revenue division, so that the regional variation could be well documented. On the basis of annual health survey 2012-13, districts were ranked as per the performance indicators (average percentage consumption of Iron Folic acid tablets by mothers and children) districts. One district from each revenue division, with poorest performances on these indicators were selected (Bhadrak District from Central division, Keonjhar District from Northen Division, Kalahandi Districts from Southern Division) and one best performing district (Jagatsinghpur District)

Selection of blocks: Within each selected districts, one good and one badly performing blocks were selected. The performance was assessed on inputs from District Collectors, CDMO/ADMO and district officials from other line departments.

Sample size calculations and sampling: Assuming prevalence of anemia as 50\%, DEFF of 2 and $4 \%$ nonresponse rate, the calculated sample size was 800 each for 4 groups of beneficiaries namely adolescent boys, adolescent girls, pregnant women and lactating women. In addition to this, 800 Women of reproductive age group (WRA) were chosen as eventually the program would be rolled out among them. A line list of all the subcentres from the selected 8 blocks in 4 districts was prepared and
50 subcentres were selected from the line list using probability proportionate to size (PPS) sampling method. The sample of 800 was divided equally among 50 subcentres and 16 respondents were chosen from each subcentre. Depending on the number of villages from each subcentre, number of respondents were calculated for each village.

Households were checked until the adolescent girls were encountered. If there were two adolescent girls in the same house, then Kish grid method was used to select one of them randomly and the next adjacent home was visited to recruit the second respondent. This process was repeated for adolescent boys and women of reproductive age groups while pregnant and lactating women were chosen randomly from the line list available from the frontline worker of that village.

Data collection: Before the collection of data, a 6 days phase-wise training was provided. Research team prepared a questionnaire and it was translated as per local language. Separate questionnaire to investigate the coverage and compliance to NIPI interventions, beneficiaries' health seeking behaviour with regard to anemia detection and treatment was developed for different beneficiaries' groups. The ANMs of the selected sub-centres and ASHA / AWW of selected villages were approached within the subcentre for interviews using the pretested and semi-structured interview schedule. Hemoglobin estimation of subject was done using Hemocue 201. After the finger prick, first two drops of blood were removed to ensure that the sample was based on fresh capillary blood and a single drop of blood was taken and placed into a cuvette for measurement. The estimated Hemoglobin was compared to WHO cut-offs to estimate anemia prevalence. (12)

Data analysis: Data was analysed using Microsoft excel. The categorical data was represented in the form of frequency and percentages.

Ethical approval and informed consent: The process documentation was approved by the Institutional Ethics Committee of AlIMS, Bhubaneswar. Informed consent was taken from all study participants and confidentiality was maintained.

Ethical approval letter number: T/EM-F/CMFM/15/18 Dated 29.02.2016

\section{Results}

A total of 3974 beneficiaries from four districts of Odisha were interviewed regarding the knowledge about anaemia symptoms and hemoglobin assessment, coverage and compliance of IFA supplementation and beneficiaries' health seeking behaviour. Haemoglobin $\mathrm{Hb}$ levels were assessed and prevalence of anemia was estimated.

\section{Prevalence of anemia among beneficiaries}

It was observed that, prevalence of severe anemia was low (1-3\%), but the prevalence was very high in moderate 
(7-20\%) and mild anemia (39-58\%) categories with an overall prevalence of $70.0 \%$ (Figure 1). Anemia was most prevalent among lactating mothers (77\%), followed by women of reproductive age group (71\%), pregnant women (69\%) and adolescent girls (68\%).

\section{Prevalence of anemia by districts}

Among the four districts, highest prevalence was observed in Keonjhar (75-87\%), with similar pattern amongst the other districts in Jagatsinghpur, Bhadrak and Kalahandi (57-81\%). Among the individual beneficiarydistrict groups, lowest prevalence of anemia was observed among pregnant women in Jagatsinghpur (57\%) and highest prevalence was among lactating women in Keonjhar (87\%) (Figure 2)

\section{Knowledge of symptoms among beneficiaries}

Less than $20 \%$ of these respondents reported knowing the symptoms of anemia. The beneficiaries felt that, the most common manifestations of anemia were giddiness, weakness or tiredness (13\%-20\%). Beneficiaries relating poor scholastic performance with anemia was low $(0 \%-3$ \%).(Table 1)

\section{Knowledge about hemoglobin assessment}

Only $50-62 \%$ of beneficiaries interviewed, knew of any blood test for anemia diagnosis. Among those who knew that there was a blood test for anemia most said they would prefer visiting a government doctor at a health center for treatment (85\%-95\%). Of those who sought $\mathrm{Hb}$ testing in the last six months, $55 \%$ were pregnant women and $37 \%$ lactating mothers only, 9\% adolescent girls, $4 \%$ adolescent boys, and 9\% other WRA had been investigated for anemia.

\section{Preferred providers for anaemia related symptoms} Majority of the subjects said they preferred a government doctor in health centres (86-97\%), while $2-9 \%$ subjects said they preferred a private doctor (2-9\%) for any healthrelated issues. (Table 1 )

\section{Coverage of IFA supplements and reasons for low coverage}

Coverage of IFA supplementation was estimated among adolescent and adult beneficiaries. Among beneficiaries interviewed, $38 \%$ of adolescent girls, $16 \%$ of adolescent boys, $73 \%$ of pregnant women, $46 \%$ of lactating mothers, and $11 \%$ of WRA indicated they had consumed IFA tablets in the previous month. In addition, 39\% of WRA had children under five and $52 \%$ of these children received IFA syrup in the last month. (Table 1)

The most common reason cited for not consuming IFA tablets among adolescent boys and girls were being holiday in the school due to vacation (31\% among adolescent girls and $28 \%$ among adolescent boys) while among pregnant and lactating women, "not informed" (42\% among lactating women and $21 \%$ among pregnant women) was the most common reason. (Table 1)

\section{Discussion}

This descriptive cross-sectional study inferred that anemia was highly prevalent among women and adolescent girls (68-77\%). Most were mildly anemic (39-58\%), many were moderately anemic (7-20\%) and frequency of severe anemia was quite low (1-3\%) with an overall prevalence of $70.0 \%$.

As per NFHS 4 Odisha report, prevalence of mild, moderate and severe anemia among pregnant women were $24.0 \%, 22.7 \%$ and $0.8 \%$, respectively and in lactating women were $44.8 \%, 9.5 \%$ and $0.6 \%$, respectively.(13) The prevalence of moderate and severe anemia was in consistent with other results. When compared with NFHS3 Odisha state facts, (prevalence of mild, moderate and severe anemia among pregnant women were $37.1 \%$, $29.6 \%$ and $2.0 \%$, respectively whereas lactating women it was $47.3 \%, 16.1 \%$ and $1.6 \%$ respectively). A reduction in prevalence of severe anemia was $60 \%$ and $62.5 \%$, moderate anemia; $23.3 \%$ and $41 \%$, mild anemia: $36.4 \%$ and $5.2 \%$ among pregnant women and lactating mothers respectively. (14) Thus, in the present state it is evident that, the prevalence of severe anaemia reduced drastically followed by moderate anemia and mild anemia. There is a definite transition of grades of anemia among the beneficiaries from severe anemia to moderate anaemia, from moderate anaemia to mild anemia and from mild anaemia towards normal hemoglobin status.

In the present study, out of the four districts, four-fifth of the women were having anaemia in Keonjhar district (75\%). However, NFHS 4 report among four districts, prevalence of anemia was highest in Kalahandi (68.7\%) followed by Bhadrak (43.5\%), Keonjhar (40.5\%) and Jagatsinghpur (35.8\%). (13)

In this study, less than $20 \%$ of the beneficiaries had knowledge regarding the symptoms of anaemia. Most common symptoms felt was giddiness or weakness (13\%$20 \%)$. Study conducted by Priyadrshini V et al among adolescent girls of Keonjhar district revealed similar findings with most common symptoms known to the respondents were tiredness/body weakness (35\%).(14,15) In an another assessment of Adolescent anemia control program by Govt. of Odisha, it was revealed that most common symptoms was weakness (38.8\%). (16)

In our study, majority said they preferred a government doctor in health centres (86-97\%) if they felt anemic. This was higher as compared to a study conducted by Angadi $\mathrm{N}$ et al, where only $55 \%$ girls told they will consult doctor and take iron tablets. (17)

Only $50-62 \%$ of beneficiaries interviewed knew of any blood test for anemia diagnosis. In study conducted by Pareek $P$ et al observed only $10 \%$ respondents knew any lab test to diagnose anemia which was much lower compared to our study. (18) Similar finding were observed by Angadi $\mathrm{N}$ et al where only $34 \%$ had checked their 
hemoglobin to know their anemia status. (17) Knowledge about investigating anaemia is higher among pregnant women. Possible reason could be, pregnant women undergo $\mathrm{Hb}$ assessment at least twice during the antenatal checkup, which is free of cost under $\mathrm{RMNCH}+\mathrm{A}$ scheme.

In this study, only $38 \%$ of adolescent girls, $16 \%$ of adolescent boys, $73 \%$ of pregnant women, $46 \%$ of lactating mothers, $11 \%$ of WRA, $39 \%$ of WRA had consumed IFA tablets in the previous month. Study conducted by Mithra P et al observed $64.7 \%$ of pregnant women had consumed IFA tablets which is lower to our study findings. (19) Other studies by Pal PP et al, Malhotra $\mathrm{N}$ et al, Sonkar V K et al observed IFA consumption of $62 \%$, $67.1 \%$ and $63.14 \%$ respectively among pregnant women.(20,21,22 )Studies conducted among adolescent girls by Sevaraj $\mathrm{K}$ et al, Chakma $\mathrm{T}$ et al observed consumption of IFA tablets up to $60.6 \%, 89 \%$ respectively which were much higher as compared to our study. $(23,24)$

\section{Conclusion}

The study has shown the burden of anaemia in eastern part of India is very high because of low consumptions of IFA.

The present study shows that the prevalence of severe and moderate anaemia has decreased to a greater extent, however the prevalence of mild anaemia is still very high. This could possibly be due to lack of knowledge regarding anaemia and its symptoms among the members of the community. Many health care providers, school teachers and community members consider only severe anaemia as "anaemia" and thus the mild anaemia is relatively neglected. This brings out the need to put more efforts regarding health education and raising awareness about anaemia in the community.

\section{Recommendation}

Anemia which is considered as a silent epidemic has major impact on human health and socioeconomic development of any nation. Estimates on burden of anemia vary between countries. Though the accurate date on prevalence of anemia is essential to determine public health measures but in reality, accurate data in backward, tribal and resource par area are scarce which impedes anemia preventive strategies. This study gives a picture of anemia in a state with par health burden indicators. Thus this study will be a guiding factor for focused anemia prevention and control strategies and monitoring and progress thereafter.

\section{Authors Contribution}

VB, SPP and PBM conceived and designed the study. SPP, PBM, DPS and SB acquired and analysed the data and prepared the initial manuscript. SPP, VB, PBM and DPS revised the draft critically. All authors have read and approved the final manuscript. All authors agree to be accountable for all aspects of the work in ensuring that questions related to the accuracy or integrity of any part of the work are appropriately investigated and resolved.

\section{Acknowledgement}

The authors would like to thank all participants who participated in this study.

\section{References}

1. World Health Organization. Global Nutrition targets 2015 Anaemia Policy Brief. Glob Nutr Targets 2025 [Internet]. 2014;2(WHO/NMH/NHD/14.4):8. Available from: http://apps.who.int/iris/bitstream/10665/148556/1/WHO_NMH_ NHD_14.4_eng.pdf

2. World Health organization. the economic impact of anemia in Peru. World Health Organization. 2008. Available from: http://www.paho.org/nutricionydesarrollo/wpcontent/uploads/2013/02/The-economic-impact-of-anaemia-inPeru-GRADE-AAH-2013.pdf

3. World Health Organization. the Global Prevalence of Anaemia in 2011. WHO Rep [Internet]. 2011;48. Available from: http://apps.who.int/iris/bitstream/10665/177094/1/9789241564 960_eng.pdf?ua=1

4. Stevens GA, Finucane MM, De-Regil LM, Paciorek CJ, Flaxman SR, Branca F, Peña-Rosas JP, Bhutta ZA, Ezzati M. Global, regional, and national trends in haemoglobin concentration and prevalence of total and severe anaemia in children and pregnant and nonpregnant women for 1995-2011: a systematic analysis of population-representative data. Lancet Glob Health. 2013 Jul;1(1):e16-25. doi: 10.1016/S2214-109X(13)70001-9. Epub 2013 Jun 25. PubMed PMID: 25103581; PubMed Central PMCID: PMC4547326.[PubMed]

5. GNP. Global Nutrition Report 2017: Nourishing the SDGs. 2017;115. Available

from: https://www.globalnutritionreport.org/files/2017/11/Report_201 7.pdf

6. Indian Institute for Population Sciences. National Family Health Survey (NFHS-4). 2017;199-249. Available from: http://rchiips.org/NFHS/NFHS-4Reports/India.pdf

7. National Nutrition Monitoring Bureau. Prevalence of micronutrient deficiencies. Nutrition. 2003;(22). Available from: http://nnmbindia.org/NNMB\%20MND\%20REPORT\%202004web.pdf

8. International Institute for Population Sciences and Macro International. National Family Health Survey (NFHS-3): Volume-I [Internet]. Vol. I, Health (San Francisco). 2007. 56 p. Available from: http://scholar.google.com/scholar?hl=en\&btnG=Search\&q=intitle: National+family+health+survey+(nfhs-3)+2005?06\#0

9. Registrar General \& Census Commissioner. 2011 Census of India Executive Summary [Internet]. 2011. Available from: http://www.censusindia.gov.in/2011census/PCA/PCA_Highlights/ pca_highlights_file/Odisha/Executive_Summary.pdf

10. Indian Institute for Population Sciences. National Family Health Survey 4: State Fact Sheet, Odisha. 2015;1-6. Available from: http://rchiips.org/NFHS/pdf/NFHS4/OR_FactSheet.pdf

11. Ministry of Health and Family WelfareGuidelines for Control of Iron Deficiency Anaemia [Internet]. 2013. Available from: http://www.pbnrhm.org/docs/iron_plus_guidelines.pdf

12. Chan M. Haemoglobin concentrations for the diagnosis of anaemia and assessment of severity. Geneva, Switz World Heal Organ [Internet]. 2011;1-6. Available from: http://scholar.google.com/scholar?hl=en\&btnG=Search\&q=intitle: Haemoglobin+concentrations+for+the+diagnosis+of+anaemia+an $\mathrm{d}+$ assessment+of+severity\#1

13. National Family Health Survey (NFHS-4) Odisha. Ministry of Health and Family Welfare. 2015. Available from: http://rchiips.org/NFHS/pdf/NFHS4/OR_FactSheet.pdf

14. International Institute for Population Sciences (IIPS) and Macro International. National Family Health Survey (NFHS-3), India, 2005- 
06: Orissa [Internet]. 2008. 1-129 p. Available from: http://www.rchiips.org/NFHS/NFHS-3

Data/Orissa_state_report.pdf

15. Vijayeta P. Knowledge regarding anaemia among adolescent girls of Keonjhar city, Odisha. Int J Med Sci [Internet]. 2016;9(1):27-32. Available from: http://www.researchjournal.co.in/online/IJMS.htm NS -

16. Quick Assessment of Adolescent Anaemia Control Program (AACP) in KBK and Mayurbhanj Districts of Orissa. 131. Available from: http://www.nrhmorissa.gov.in/writereaddata/Upload/Documents /Quick\%20Assessment\%20of\%20AACP.pdf

17. Angadi N, Ranjitha A. Knowledge, attitude, and practice about anemia among adolescent girls in urban slums of Davangere City, Karnataka. Int J Med Sci Public Heal [Internet]. 2016;5(3):416. Available from: http://www.scopemed.org/fulltextpdf.php?mno=197911

18. Pareek P. A Study on Anemia Related Knowledge Among Adolescent Girls. Int J Nutr Food Sci [Internet]. 2015;4(3):273. Available from: http://www.sciencepublishinggroup.com/journal/paperinfo.aspx? journalid=153\&doi=10.11648/j.ijnfs.20150403.14

19. Mithra P, Unnikrishnan B, Rekha T, Nithin K, Mohan K, Kulkarni V, et al. Compliance with iron-folic acid (IFA) therapy among pregnant women in an urban area of south India. Afr Health Sci. 2013;13(4):880-5.
20.

Pal PP, Sharma S, Sarkar TK, Mitra P. Iron and Folic Acid Consumption by the Ante-natal Mothers in a Rural Area of India in 2010. Int J Prev Med. 2013 Oct;4(10):1213-6. PubMed PMID: 24319564; PubMed Central PMCID: PMC3843311.[PubMed]

21. Malhotra N, Upadhyay RP, Bhilwar M, Choy N, Green T. The role of maternal diet and iron-folic acid supplements in influencing birth weight: evidence from India's National Family Health Survey. J Trop Pediatr. 2014 Dec;60(6):454-60. doi: 10.1093/tropej/fmu051. Epub 2014 Sep 29. PubMed PMID: 25266114.[PubMed]

22. Sonkar VK, Khan NM, Domple VK, Inamdar IF. Knowledge and practices of pregnant women regarding the iron supplementation during pregnancy. Int J Community Med Public Heal. 2017;4(8):2891-4.

23. Selvaraj K, Arumugasamy P, Sarkar S. Compliance and patterns of iron-folic acid intake among adolescent girls and antenatal women in rural Tamil Nadu. CHRISMED J Heal Res [Internet]. 2017 [cited 2018 May 29];4(2):87. Available from: http://www.cjhr.org/text.asp?2017/4/2/87/201996

24. Chakma T, Vinay Rao P, Meshram PK. Factors associated with high compliance/feasibility during iron and folic acid supplementation in a tribal area of Madhya Pradesh, India. Public Health Nutr. 2013 Feb;16(2):377-80. doi: 10.1017/S1368980012002704. Epub 2012 May 28. PubMed PMID: 22640719.[PubMed]

\section{Tables}

TABLE 1 KNOWLEDGE OF CLINICAL PRESENTATION OF ANEMIA, PREFERRED PROVIDERS FOR ANEMIA RELATED SYMPTOMS, COVERAGE OF IFA SUPPLEMENTATIONS AND REASONS FOR LOW COVERAGE AMONG BENEFICIARIES (IN \%)

\begin{tabular}{|c|c|c|c|c|c|c|}
\hline & & $\begin{array}{l}\text { Adolesce } \\
\text { nt Boy } \\
(n=800)\end{array}$ & $\begin{array}{l}\text { Adolescent } \\
\text { Girls } \\
(n=800)\end{array}$ & $\begin{array}{l}\text { Pregnant } \\
\text { Women } \\
(n=786)\end{array}$ & $\begin{array}{l}\text { Lactating } \\
\text { Women } \\
(\mathrm{n}=788)\end{array}$ & $\begin{array}{l}\text { WRA } \\
(n=800)\end{array}$ \\
\hline \multirow{7}{*}{$\begin{array}{l}\text { Knowledge of clinical } \\
\text { presentation of anemia } \\
\text { among beneficiaries (in \%) }\end{array}$} & Pale appearance & 4 & 7 & 2 & 3 & 11 \\
\hline & Giddiness & 14 & 17 & 19 & 18 & 17 \\
\hline & Palpitation & 2 & 2 & 2 & 3 & 3 \\
\hline & Weakness & 13 & 18 & 20 & 19 & 19 \\
\hline & Tiredness & 10 & 13 & 15 & 15 & 15 \\
\hline & Reduction in work efficacy & 2 & 4 & 4 & 4 & 5 \\
\hline & $\begin{array}{ll}\begin{array}{l}\text { Poor } \\
\text { performances }\end{array} & \text { scholastic }\end{array}$ & 3 & 2 & 0 & 0 & 1 \\
\hline \multirow{5}{*}{$\begin{array}{lr}\text { Preferred } & \text { provider for } \\
\text { anaemia } & \text { related } \\
\text { symptoms } & \end{array}$} & ANM & 0 & 0 & 1 & 1 & 1 \\
\hline & AWW & 0 & 0 & 1 & 1 & 1 \\
\hline & ASHA & 1 & 1 & 4 & 4 & 4 \\
\hline & Private doctors & 2 & 2 & 9 & 7 & 4 \\
\hline & Govt. doctors & 97 & 97 & 86 & 87 & 90 \\
\hline $\begin{array}{l}\text { Coverage of IFA } \\
\text { supplements and reasons } \\
\text { for low coverage }\end{array}$ & & 38 & 16 & 73 & 46 & 11 \\
\hline \multirow{7}{*}{$\begin{array}{l}\text { Reasons for not consuming } \\
\text { IFA tablets during the last } \\
\text { month }\end{array}$} & Not Informed & 37 & 18 & 21 & 42 & \\
\hline & Dislike taste & 4 & 17 & 7 & 8 & \\
\hline & Fear of side effect & 1 & 2 & 6 & 2 & \\
\hline & Vacation & 28 & 31 & 0 & 0 & \\
\hline & Not available & 0 & 0 & 15 & 15 & \\
\hline & Others & 12 & 15 & 14 & 10 & \\
\hline & Not reported & 19 & 18 & 37 & 25 & \\
\hline
\end{tabular}




\section{Figures}

FIGURE 1 PREVALENCE OF ANEMIA IN DIFFERENT GROUPS

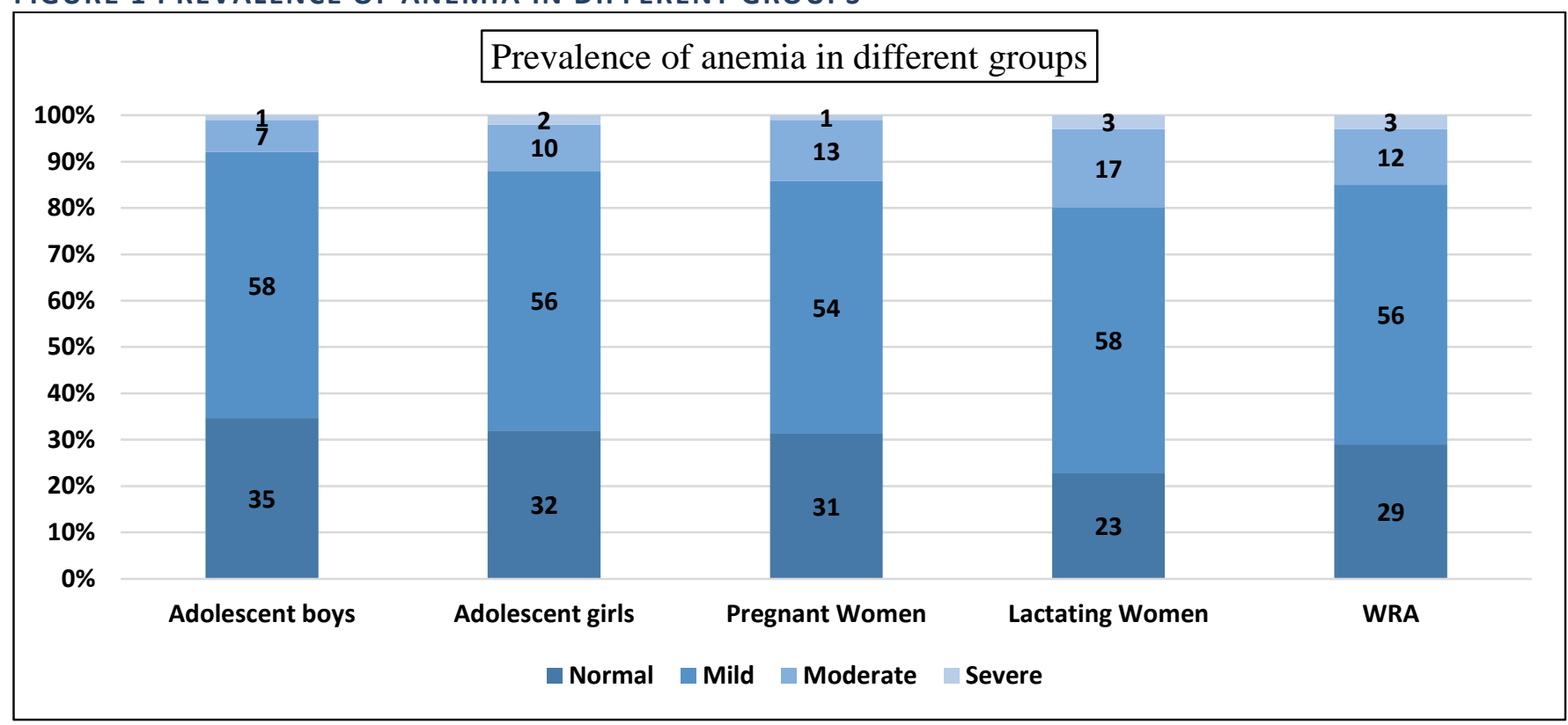

FIGURE 2 PREVALENCE OF ANEMIA BY DISTRICTS

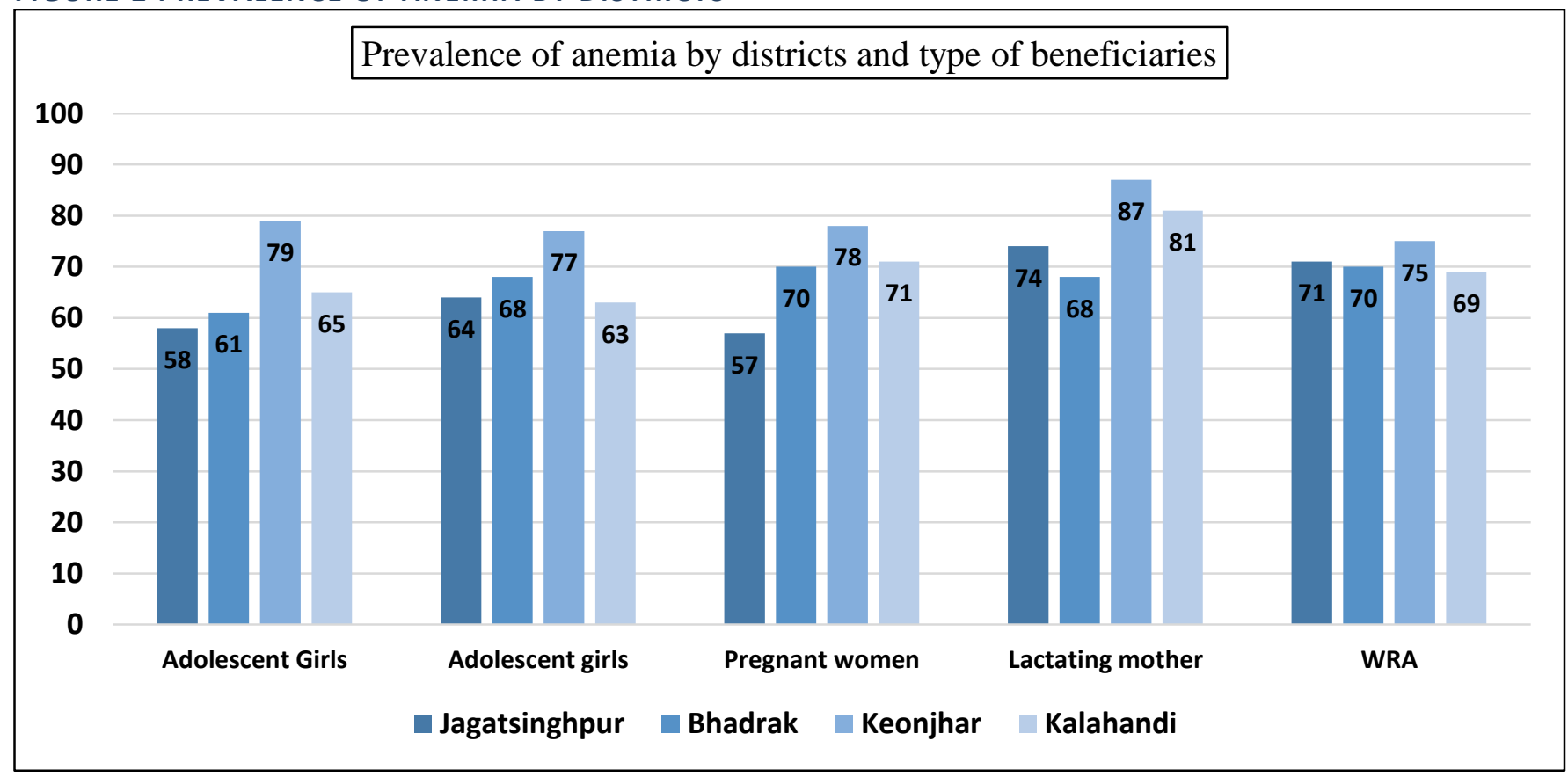

